\title{
O ATOMISMO HERÉTICO DE GALILEU GALILEI
}

\author{
Eduardo Simões ${ }^{1}$ \\ Faculdade de Ciência e Tecnologia de Montes Claros (FACIT) \\ https://orcid.org/0000-0001-7375-8574
}

\begin{abstract}
RESUMO:
O objetivo do presente artigo é o de analisar a contraposição instituída por Galileu ao aristotelismo tomista vigente na Idade Média e apresentar seu atomismo em alternativa à física das qualidades secundárias. $\mathrm{O}$ físico florentino, cujas preocupações restringiram-se ao campo da Física, vê-se envolvido numa querela de ordem religiosa (a negação do "fenômeno eucarístico") que o leva à condenação por traição, cuja pena consistiu na abjuração pública e na prisão domiciliar perpétua. Iremos analisar, baseados nos estudos de Pietro Redondi (1991), como a história da condenação de Galileu, na verdade, não está necessariamente vinculada à defesa do heliocentrismo copernicano. Para além das fronteiras dessa noção, existiu todo uma trama tecida pelo protecionismo religioso, primazia eclesiástica, vedetismo e inveja.
\end{abstract}

PALAVRAS-CHAVE: Galileu; Atomismo; Qualidades secundárias; Heresia; Condenação.

\section{THE HERETIC GALILEO GALILEI ATOMISM}

\begin{abstract}
:
The purpose of this article is to analyze the opposition instituted by Galileo to the prevailing Thomistic Aristotelianism in the Middle Ages and present his alternative to atomism in physics of secondary qualities. The Florentine physicist, whose concerns were restricted to the field of physics, we see involved in a complaint of religious order (the negation of "Eucharistic phenomenon") that leads to the conviction for treason, the penalty for which
\end{abstract}

\footnotetext{
${ }^{1}$ Doutor em Filosofia pela Universidade Federal de São Carlos (UFSCar), São Paulo Brasil. Professor e coordenador de pesquisa da Faculdade de Ciência e Tecnologia de Montes Claros (FACIT), Minas Gerais. Atua especialmente em Filosofia da Ciência e Tecnologia, Epistemologia, Lógica e Filosofia da Linguagem. E-mail: eduardsimoes@yahoo.com.br
} 
was the public recantation and house arrest perpetual. We will consider, based on studies of Redondi Pietro (1991), as the story of Galileo's condemnation, in fact, is not necessarily linked to the defense of the Copernican heliocentrism. Beyond the boundaries of this notion, there was all a plot woven by religious protectionism, ecclesiastical primacy, stardom and envy.

KEYWORDS: Galileo; Atomism; Secondary Qualities; Heresy; Condemnation.

Introdução

A filosofia grega que entra em declínio no Período Helenístico com as invasões bárbaras agoniza de vez no Período Greco-Romano com a ascensão da filosofia cristã. Em Plotino encontramos o último suspiro da tentativa do pensar independente. Com isso, inaugura-se na Idade Média o famigerado movimento patrístico que transcorre do século II ao século VIII depois de Cristo. Trata-se de um período onde a Igreja, precisando de se firmar enquanto instituição político-religiosa, em um ambiente pagão pósinvasões germânicas, vai buscar na filosofia grega argumentos racionais em vista da defesa das verdades cristãs. É nesse cenário que surgem os chamados padres da Igreja: intelectuais convertidos que empregam toda força na defesa racional da fé.

Com Justino, Clemente de Alexandria, Orígenes, Gregório de Nazianzo, Gregório de Nissa, Basílio Magno, Agostinho, entre outros, vê-se alvorecer um grande contingente de Apologias: alegado jurídico cujas argumentações visavam obter dos imperadores o reconhecimento do direito legal que os cristãos teriam para existir em um império oficialmente pagão. É nesse período que se vê a perversão sistemática da filosofia grega em vista dos interesses cristãos. Os pensamentos pressupostamente "religiosos" de Pitágoras, Platão, Epicuro, Zenão de Cítio e Pirro de Élida foram cristianizados, desaparecendo de vez a aplicação da razão nos diversos campos (como haviam feito os gregos), para lhe empregar somente em um campo. Agora não mais existem os "amantes da sabedoria" (filósofos), na acepção típica dos gregos, e sim, pesquisadores e comentadores das obras produzidas pelos antigos mestres. Inicia-se um período de calmaria do pensamento criativo em prol de um trabalho de reordenamento, de interpretação (exegese) das obras dos predecessores gregos.

Os ditos "problemas filosóficos" que ora em diante ocupam os padres da Igreja são os da existência e cognoscibilidade de Deus, da criação do mundo e da natureza, da origem do mal, do corpo e da alma, da verdade do cristianismo etc., e tudo foi feito para que os argumentos racionais gregos 
viessem endossar as certezas cristãs. Um típico exemplo do que acontecia, encontra-se em Gregório de Nissa (335-394). Utilizando-se da divisão dicotômica de Platão e Aristóteles dos mundos intelectivo e sensível, ele define o homem como sendo de natureza espiritual e material, reforçando seu argumento com os elementos muito utilizados na cosmologia présocrática (fogo, ar, água e terra). "O homem pertence, através do seu corpo (água e terra), ao mundo da natureza, e por este pertencer, Deus já está presente nele. Mas o homem pertence também ao mundo do espírito (ar e fogo), havendo, portanto, nele, um 'Nous'," (apud SPINELLI, 1990, p. 76) ${ }^{2}$. Certo é que não somente os pensamentos de Platão e Aristóteles, ou dos présocráticos, são utilizados pelos pensadores da Igreja nascente. Os padres se apropriam, também, de elementos da ontologia grega, da teodiceia, da dialética, da ética, da metafísica - tudo em prol da "sistematização" de uma nova filosofia que agora passa a ser serva da teologia. Mas, felizmente, ao lado do que os comentadores exegetas "produziram", ainda sobreviveram os pensamentos dos doutos "cientistas" que abriram margem para outros tipos de estudos que afloraram no decorrer da Idade Média. É o caso da geometria, aritmética e astronomia (Euclides, Aristarco, Arquimedes e Ptolomeu).

Outro movimento intelectual erigido na Idade Média foi a Escolástica, assim nomeada, em designação aos chamados "escolásticos", professores das escolas da época. O movimento escolástico inicia-se no século VIII quando Carlos Magno resolve organizar o ensino por seu império e fundar escolas ligadas às instituições católicas. Analfabeto até a idade adulta, tendo sua preocupação sempre voltada para a arte da guerra, mesmo assim, promoveu o desenvolvimento cultural do Império Franco abrindo escolas e mosteiros, estimulando a tradução de obras antigas, patrocinando o trabalho dos artistas e investindo na cultura. Esse seu trabalho de estímulo à atividade cultural recebeu no nome de Renascença Carolíngia.

O modelo escolástico que, no início, foi organizado pelo copista e erudito inglês chamado Alcuíno (735-804), a mando de Carlos Magno que desejava organizar a "Escola Palatina" (fundada em 782), funcionava da seguinte maneira: privilegiava-se primeiramente o estudo da linguagem com o Trivium que enfatizava a gramática, a retórica e a dialética; depois partia para o exame das coisas com o Quadrivium que enfatizava o estudo da geometria, da aritmética, da astronomia e da música. Quanto ao método de ensino, esse se desenvolvia em dois momentos fundamentais: a lectio, significando leitura de um texto, com interpretação dada pelo professor que analisava as palavras, destacava e comparava ideias de outros autores, e a quaestio, isto é, perguntas do didascalus aos alunos e destes ao mestre. Tratava-se de um método rigoroso, um método universitário, que ficou conhecido como "método parisiense" (modus parisiensis).

Das sete Artes Liberais promovidas pela renascença carolíngia, aquela

O atomismo herético de Galileu Galilei - Eduardo Simões 
que teve mais destaque e importância, renome e utilização, foi a dialética, na forma da disputatio. Essa se desenvolveu no ambiente acadêmico e sua vulgarização foi motivo de preocupação para as autoridades eclesiais.

Desde sua ascensão, com a queda do Império Romano em 476, fato que marca a transição da Antiguidade para a Idade Média, a Igreja Católica usa de subterfúgios para a manutenção do seu poder. Um desses é a própria transmissão da crença em uma verdade "revelada" que induz os menos avisados ao cultivo de uma santa ignorância, desobrigados de qualquer exercício racional, em nome da fé. Para outro exemplo, temos a instituição do Concílio que, frente a algo que pudesse contrariar as "verdades" da fé, submetia esse algo à discussão e à possível regulamentação ou revogação tudo isso, para manter a todos dentro dos limites da ortodoxia e disciplinação. Tanto era que, durante alguns séculos, os estudos só se interessavam a monges e clérigos, os únicos que sabiam ler e escrever. Mesmo assim, os meios acadêmicos estavam profundamente envolvidos nas disputas dialéticas, úteis para aguçar a inteligência e a perspicácia de raciocínio. A dialética foi uma das disciplinas mais bem-sucedidas na escolaridade medieval, fruto do estudo da lógica que veio com a tradução das obras de Aristóteles (Organon, Categorias, Da Interpretação, Tópicos, etc.), lidas e difundidas nos meios acadêmicos.

Só que o sucesso da dialética, pela sua vulgarização, acabou por ultrapassar o ambiente acadêmico, tornando-se um instrumento subversivo que precisava ser atacado, uma vez que, pelos desmandos de "certos dialéticos", via-se que a lógica estava sendo sobreposta à fé. Um caso típico foi o de Pedro Abelardo (1079-1142), religioso perseguido muito mais por suas convicções heterodoxas (defendidas dialeticamente) do que por sua vida pessoal (por seu amor à Heloísa).

Em decorrência dos movimentos dialéticos e dos atos de subversividade, em 1232, a Inquisição foi instituída pelo papa Gregório IX e sua ação estendeu-se por vários reinos cristãos - Itália, França, Alemanha, Portugal e, especialmente, Espanha - com o objetivo de ver disciplinadas as opiniões e convicções pessoais dos subordinados. E foi por causa dela, como meio para se esquivar das garras dos inquisidores, que se criou a chamada "teoria da dupla verdade".

Quando os autores do século XIII tinham que prestar conta à autoridade eclesiástica sobre suas discutíveis opiniões do ponto de vista teológico, desculpavam-se dizendo que sustentaram tais opiniões em função de meros exercícios de disputa dialética (gratia exercitii, probabiliter o disputationis causa), mas sem garantir que fossem verdadeiras. Tal tipo de justificativa, todavia, surgia como consequência inevitável de ter sido a dialética, ou a disputatio, implantada como método de ensino nas universidades ${ }^{3}$.

O atomismo herético de Galileu Galilei - Eduardo Simões 
Para os "doutores eclesiásticos", inimigos da dialética, a máxima de Abelardo de que duvidando chegamos à investigação e investigando percebemos a verdade ("Dubitando ad inquisitionem venimus; inquiriendo veritaten percipimus"), não era concebível, visto que tal procedimento poderia de algum modo contrariar a "revelação".

A Inquisição que com o passar do tempo reduz suas atividades é reativada a posteriori, em meados do século XVI, diante do avanço do protestantismo. Exatamente nessa época os caminhos do Renascimento firmam-se na construção de uma nova imagem de homem e de universo.

Com o reflorescimento do comércio, o desenvolvimento da burguesia e a Reforma Protestante, a Igreja que se via enfraquecida, insistia em manter as bases do passado e refrear o progresso humano. No entanto, o que se viu foi a substituição paulatina do teocentrismo pelo antropocentrismo, da verdade revelada por aquela estabelecida pela razão, do idealismo religioso pelo materialismo racional. A natureza passa a ser observada, experimentada, pesquisada e não mais contemplada como obra da criação. Mesmo com a força brutal do Tribunal da Inquisição, os pioneiros da ciência moderna não se deixaram abater e levaram seus projetos às últimas consequências - foram os casos de Giordano Bruno (1548-1600), Nicolau Copérnico (1473-1543) e Galileu Galilei (1564-1642), que enfrentaram de perto a fúria da Igreja que insistia legislar, além de matéria de religião, em matéria de astronomia, matemática e filosofia natural. Discussões que fugiam de seu campo estrito de atuação e competência.

Mesmo diante da pressão imposta pela Igreja durante toda Idade Média, as ideias atomísticas de Demócrito, Epicuro e Lucrécio sobreviveram e de tempos em tempos manifestavam-se com toda sua força. Tais ideias estavam presentes em Cícero, no De natura deorun, onde o mesmo identifica os átomos com caracteres de ouro ou de bronze, multiformes, que pela pressão do peso podiam se inserir nos corpos dos objetos; em Galeno, no De elementis, onde a cor e o sabor eram opiniões e os "átomos e o vazio, verdades"; em Giordano Bruno, no De mínimo, onde, como em Lucrécio, para ler o universo bastava combinar um número bastante reduzido de caracteres ou de letras para formar inumeráveis espécies; em Telesio, no De rerum natura iuxita propria principia, onde a causa do calor seria pela emissão de partículas de fogo e de outros elementos, tanto do céu como da terra. Essas são apenas algumas das muitas manifestações do atomismo na Idade Média e todas elas tinham um fundo lucreciano que fora muito difundido por toda essa Idade. O De rerum natura de Lucrécio que era muito citado na universidade e muitíssimo lido fora dela, "fora condenado pela Igreja no V Concílio de Latrão e depois condenado novamente, porque continuava sendo muito difundido e lido, pelo Sínodo Florentino de 1518 ". Mas, o que é que tinha de tão perigoso no atomismo de Lucrécio? O caso Galileu nos dará uma resposta. 


\section{Galileu Herético?}

Se se conhece a história de Galileu, sabe-se muito bem sobre sua condenação: fora condenado em 1632 porque com seu Dialogo desobedeceu à ordem expressamente imputada pelo inquisidor, cardeal Bellarmino, que em 1616 teria lhe proibido de desenvolver e/ou propagar qualquer ideia de cunho copernicista, isto é, qualquer ideia que visasse retirar a terra do centro do universo (lugar escolhido por Deus para a obra de sua criação). Por sua desobediência, foi condenado à prisão domiciliar perpétua por alta traição e obrigado abjurar-se publicamente. Pelo menos é isso que os historiadores da ciência nos apresentam em seus livros-textos.

Pietro Redondi em seu Galileu Herético (1991) nos apresenta outra versão da condenação de Galileu a partir de um documento, até então secreto, que ele mesmo teria descoberto no Vaticano: a de que a condenação de Galileu deu-se por sua adesão às doutrinas atomistas de Demócrito, Epicuro e Lucrécio. Resumidamente, o que teria ocorrido fora o seguinte: a filosofia oficialmente aceita no período escolástico, principalmente depois de Tomás de Aquino, era a de Aristóteles. Lia-se e comentava em todas as universidades e ordens religiosas os Primeiros e segundos analíticos, o De anima, a Física, o De generatione et corruptione, os Meteorológicos, mas tudo era interpretado sob a luz da fé católica. O neófito Aristóteles que respondia todas as controvérsias e endossava todas as teorias, tinha resposta para tudo: magister dixit! ( $O$ mestre disse!), esse era o lema. Mas, os interesses filosóficos de Galileu eram outros que não Aristóteles. Interessava-se pelo atomismo físico que representava uma perspectiva renovadora frente ao que era oficialmente oferecido: a concepção aristotélica de mundo. Importava-se, portanto, com o De rerum natura de Lucrécio e com o Pneumatica de Héron de Alexandria ${ }^{5}$. Em seu Discorso sulle cose che stanno in sull'acqua (1612), Galileu havia submetido a validade das ideias de Demócrito sobre o calor composto de átomos de fogo ao teste da hidrostática:

\footnotetext{
O resultado, com alguma crítica e reserva, fora encorajante: o atomismo era uma hipótese de pesquisa legítima e fecunda para apresentar as qualidades da física como ações cinéticas e mecânicas de corpúsculos materiais. Tratava-se de transformar aquela hipótese num programa teórico suficientemente geral que se tornasse uma máquina de guerra eficaz em física contra a concepção aristotélica do mundo ${ }^{6}$.
}

E foi justamente isso que Galileu fez. Ele que particularmente jamais apresentou uma teoria sistemática sobre a natureza da luz, havia apresentado em 1611 uma experiência de ótica física que impressionou os aristotélicos: foi a experiência da pedra luminescente de Bolonha (sulfato de Bário). Essa $\mathrm{O}$ atomismo herético de Galileu Galilei - Eduardo Simões 
pedra depois de ter sido exposta à luz do dia poderia brilhar na obscuridade; e aquela luz brilhando na escuridão poderia ser dissociada da ideia de calor ou de uma fonte luminosa, o que acabara por abalar a "verdade" aristotélica da luz como uma qualidade de um meio transparente iluminado. "Em vez de uma qualidade, era um corpo 'quantum' e se propagava, portanto, mediante uma emissão de corpúsculos invisíveis"”.

Em sua Física Aristóteles professa o que é chamado de realismo metafísico; e todos os fenômenos físicos são entendidos em termos de qualidades sensíveis: todas as qualidades (cor, sabor, cheiro, calor, dureza, etc.) são inerentes a uma substância e nenhuma qualidade pode existir sem ela. Tais qualidades, mesmo sendo apresentadas de infinitas maneiras aos sentidos, mantém entre si algumas formas fundamentais (são quentes ou frias, secas ou úmidas). A física, portanto, é o estudo do movimento das coisas materiais que compõem o mundo. Os dados dos sentidos podem ser conhecidos e são os mais dignos de fé. Os elementos fundamentais da física aristotélica são os mesmos de Empédocles: água, ar, terra e fogo; cada um, por sua própria natureza tende a ocupar o seu "lugar natural" (o que explica porque o fogo e o ar sobem; ou porque a água e a terra descem). Estes elementos podem se converter uns nos outros dada a troca de qualidades que lhes são comuns, por exemplo, um corpo frio em movimento rápido aquecese porque, movendo-se, recebe do ar quente e úmido a qualidade de ser quente. Há uma constante passagem de um elemento a outro, num movimento circular que imita, a seu modo, o movimento circular das esferas celestes. O que se vê são as inúmeras diferenças que nos são apresentadas pela realidade, por exemplo, de cor, de odor, de fluidez, de dureza e assim por diante; e todas elas, eram explicadas, obscuramente, por essas sucessíveis mudanças de qualidade.

Mas, Galileu não estava em conformidade com afirmações desse tipo. Em seu livro Saggiatore, publicado em 1623 com a aprovação do Santo Ofício, defendia uma teoria muito diversa da teoria física aristotélica. Com relação ao calor, por exemplo, ao invés de concebê-lo fruto do movimento, associa-o à emissão de partes muito sutis de substância. O calor é produzido quando a fricção entre dois corpos é tão forte que desprende algumas partículas de matéria. Essas "partes sutis", ou partículas, eram designadas por Galileu pelos termos "partículas ígneas", "minima ígneos", "minima sutilíssimos", "minima quant"; somente com relação à luz ele usava expressamente a palavra átomo - o que não inviabiliza, em hipótese alguma, sua postura atomista. $\mathrm{O}$ calor enquanto dado do sentido (bem como a cor, o odor, o sabor) não eram para Galileu mais do que intuições subjetivas promovidas pelos órgãos dos sentidos e sua tácita constituição devia-se a causas atômicas. Com isso, "o Saggiatore propunha definitivamente substituir a física aristotélica traduzindo suas proposições predicativas que diziam respeito a experiências de qualidades para uma nova linguagem: 'o 


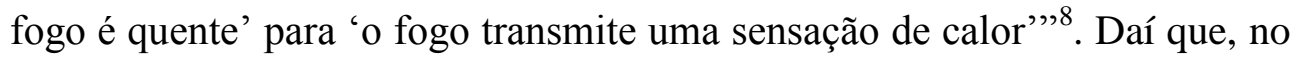
novo vocabulário galileano, as qualidades aristotélicas de branco, doce, quente, etc. ganham status apenas de nomes - tais palavras são nomes e nada mais do que isso (vale lembrar que Galileu é representante do nominalismo escolástico medieval). Tais qualidades são simplesmente estímulos sensíveis erroneamente atribuídos, por Aristóteles, ao mundo objetivo.

Galileu não havia percebido em qual arena entrava e acabou, mesmo sem intenção, por tocar em um tema melindroso sobre o qual há séculos a Igreja havia firmado uma ortodoxia: o tema da Eucaristia. É aqui que entra em cena a figura do padre Orazio Grassi, da Companhia de Jesus, que promove uma perseguição a Galileu que perdurará até sua condenação definitiva em 1632. O Saggiatore teve uma aceitação imediata do mundo intelectual de sua época, contou com a aprovação das mais altas autoridades eclesiásticas, além da aprovação do papa. Mas, sua história retroage há alguns anos antes, em 1618, quando da passagem de três cometas.

Naquela época o padre Orazio Grassi, aproveitando um estudo precedente de Tycho Brahe que em 1577 havia conjecturado sobre o movimento desses corpos, decide aperfeiçoar sua teoria e explicar aquele fenômeno que tinha surpreendido o público da época. Sem entrar em maiores detalhes sobre as teorias em jogo, sabe-se ${ }^{9}$ que os sistemas, tanto de Brahe como de Grassi (esse expresso em De tribus cometis anni MDCXVIII disputatio astronomica habita in Collegio romano - 1619), atingiam frontalmente a teoria de Copérnico sobre o movimento da terra. Teoria essa tinha a adesão de Galileu a ponto dele receber, em 1616, uma advertência do cardeal Bellarmino para o abandono da teoria heliocêntrica. Mas o que fazer para paralisar as tentativas de Grassi de sobrepujar o heliocentrismo de Copérnico? O que fazer para que Copérnico não fosse desacreditado? Parece que a única opção era atacar de frente a astronomia dos adversários. E com qual teoria? Qualquer uma que "demonstrasse" o movimento circular dos cometas em torno do sol. Para isso, "havia uma muito sedutora, atribuída a Demócrito e Anaxágoras, que explicava os cometas como aglomerados estelares"10, que não foi escolhida por Galileu. Preferiu, em um Discorso delle comete, através de um interposto (seu aluno Mario Guiducci), negar a existência física dos cometas atribuindo-lhes somente a condição de aparências luminosas, meteoros óticos subjetivos, simulacros, puros reflexos sobre vapores, sem nenhum aspecto térmico devido ao movimento. Teoria esdrúxula, é claro, para qualquer teoria moderna sobre cometas. Mas que não era qualquer "opinião" lançada ao vento ao sabor de conjecturas irresponsáveis. Por trás de sua teoria havia uma robusta matemática aliada à física com um tempero dialético digno dos maiores literatos. $\mathrm{O}$ efeito pretendido por Galileu foi alcançado: havia ridicularizado seu adversário e, por extensão, toda ordem dos jesuítas, composta pelos mais famosos 
teólogos, filósofos e cientistas da época - sem contar que era ela quem tinha maior influência sobre o Santo Ofício e, consequentemente, sobre o tribunal da Inquisição.

Desse momento em diante, não faltaram tentativas, por parte de Grassi e dos jesuítas, de colocar os escritos de Galileu no Índex romano. A hostilidade de Galileu à filosofia de Aristóteles, oficialmente aceita pela Igreja e difundida pelos jesuítas, era conhecida, mas dessa vez ele tinha ido longe demais. E o começo da contraofensiva jesuítica dá-se com uma obra do padre Grassi, assinada com o pseudônimo de Lotario Sarsi (provavelmente para não comprometer o Colégio Romano com controvérsias desse tipo, visto que, uma vez sendo aceito pelo próprio papa, questioná-la seria questionar o seu pontificado), e intitulada Libra astronômica ac philosophica (1619). O interessante é que por trás de toda uma argumentação sobre a natureza dos cometas, onde o autor invoca dos pitagóricos a Tycho Brahe para o seu auxílio argumentativo, vê-se escondida uma polêmica que extrapola o campo científico e deságua no campo religioso. "O misterioso Sarsi traz uma invencível propensão a introduzir na polêmica científica suposições hipócritas e insinuações sobre opiniões religiosas do adversário" " "Galileu é um herético" e sua heresia dá-se no ponto em que o seu escrito atinge frontalmente o mistério do Santíssimo Sacramento (a Eucaristia): esse era o resumo da acusação.

Essa acusação era grave e gerou uma série de controvérsias a respeito da teoria que ali se encontrava. Tais controvérsias obrigam Galileu a mais tarde reescrever o Discorso, alterando e aperfeiçoando sua posição, através da obra intitulada Saggiatore. Como foi dito, esse seu escrito teve aceitação imediata, foi autorizado pelas autoridades eclesiais do Santo Ofício, recebeu o imprimatur, e, para endossar de fato seu conteúdo, foi "abençoado" pelo papa Urbano VIII (amigo de Galileu) que, na época, estava disposto a conviver com as novidades advindas da filosofia natural. Sem entrar nos detalhes técnicos acerca das questões astronômicas ali tratadas, a antiga ideia das qualidades aristotélicas serem apenas nomes permanece intocada nessa nova obra: cor, odor, sabor, etc. são expressões de estados subjetivos e nada mais, isto é, são apenas nomes; ilegitimamente atribuídos ao mundo objetivo. Galileu dá um exemplo: as cócegas produzidas por uma pena quando atritada com o nariz ou nos pés são apenas sensações, na pena propriamente dita não é encontrada nenhuma propriedade como essa. $\mathrm{O}$ mesmo vale para o calor: "o calor é produzido pela dissolução de um corpo em partes finíssimas. No caso de sua percepção sensível não se trata de uma modificação de propriedade ou de estado, mas da penetração da carne com maior ou menor intensidade" 12 . Mas, o que isso tem a ver com heresia? Onde entra a Eucaristia nessa história? Procede a acusação de Grassi?

Por trás dos termos cor, odor, sabor havia séculos de debate Eucarístico. A palavra transubstanciação sancionada pelo Concílio de 
Latrão em 1215 e afirmada como dogma era, por séculos, oficiosamente difundida e vivenciada pelos católicos. Com o Concílio de Trento (15451563), no movimento de Contrarreforma, vê-se definitivamente estabelecida como doutrina certa. Mas, que querela estava por trás dessa palavra? Tratase de um dogma que torna flagrante a antinomia entre o testemunho dos sentidos e a fé doutrinal. Uma filosofia da matéria segundo a qual há nos corpos uma realidade fundamental que os constitui e uma realidade aparente aos sentidos: substância e qualidades (ou espécies, propriedades). Como conceber que depois da "fórmula" pronunciada pelo sacerdote, aquelas substâncias, pão e vinho, venham se transformar em corpo e sangue de Cristo? As espécies eucarísticas, ou as qualidades eucarísticas (cor, sabor, odor - qualidades secundárias), são realidades objetivas ou impressões subjetivas? Tudo o que no rito denomina-se transubstanciação parece trair os nossos sentidos, restando somente a fé para salvaguardar. Mais uma vez, está colocado o embate entre a fé e a razão.

No entanto, para a doutrina católica a realidade eucarística não é essa: existe ali, de fato, uma mudança de substância, não é só uma questão de fé. E o argumento utilizado para tal defesa, evidentemente, é o do aristotélico Tomás de Aquino:

São Tomás tinha a audácia intelectual de afirmar aquilo que os seus predecessores (...) haviam apenas timidamente exposto: os fenômenos eucarísticos são fenômenos sensíveis separados da substância, acidentes sem sujeito. Portanto, a quantidade (extensão) da hóstia consagrada não é mantida nem pela matéria do pão nem pelo ar ambiente. Ela permanece milagrosamente, sem substância. Assim também todos os outros acidentes aderentes à extensão: os famigerados "cor, odor, sabor". Estes persistem e agem "como se" dependessem de uma substância, mas na realidade persistem e agem sem substância $^{13}$.

Acidentes (cor, odor, sabor) sem sujeito, matéria sem extensão, acidentes sem substância (...) trata-se de uma saída um tanto quanto obscura, mas racionalmente projetada, que havia abrigado o mistério eucarístico longe das controvérsias dos hereges. Mas, o que Galileu havia a dizer sobre essa questão que o incriminaria e o tornaria suspeito de heresia? Na verdade, o Saggiatore não trata diretamente de nenhuma dessas questões. O orgulho ferido de Grassi foi quem assim o interpretou com o objetivo último de incriminá-lo - uma derrocada contra o golpe que sofrera no passado. Sua pretensão foi a de acusar o Saggiatore de afirmar "expressamente" a teoria subjetiva das qualidades sensíveis também para os acidentes eucarísticos e professar o atomismo substancial "homeômero" de Anaxágoras. Daí que a acusação era a de que a "doutrina de Galileu não é compatível com a existência dos acidentes eucarísticos estabelecidos pelo cânone 2 da XVIII 
Sessão do Concílio de Trento"14. A grande questão era: se para a doutrina a matéria é transubstanciada após a consagração, não subsistirá nenhuma matéria do pão e do vinho depois da mesma, e os acidentes (cor, sabor, odor), por extensão, também não subsistirão. Mas, se interpretarmos em termos atômicos, assim como pensa o Saggiatore, que, reitera-se, não está preocupado com a questão do dogma eucarístico, estas "partículas mínimas" de substância, responsáveis pelos acidentes eucarísticos, permanecerão mesmo após a consagração. E o que se entende por acidentes (ou qualidades), são apenas sensações de estados subjetivos. Objetivamente o que se tem são apenas partículas (ou átomos) de pão na hóstia, mesmo depois de consagrada - não há uma verdadeira transubstanciação - “(...) a permanência de partículas de substância explicando os acidentes sensíveis implica a permanência do pão e do vinho mesmo após a consagração. Então não haveria nenhum milagre (...)" ${ }^{\prime 15}$. E as aparências externas - cor, sabor, e odor - seriam apenas nomes.

Tais acusações foram suficientes para que Galileu fosse taxado de herético. No entanto, nenhum processo formal foi levantado contra Galileu (somente uma representação anônima, provavelmente do padre Orazio Grassi, foi apresentada), isso porque, questionar uma obra amplamente aprovada e endossada pelo papa, seria afrontar a própria autoridade de Urbano VIII que era amigo do cientista florentino.

Com o passar do tempo, mais especificamente em 1632, o papa enfrenta uma grande crise política motivada pela Companhia de Jesus e encabeçada pelo cardeal Borgia, protetor da Espanha ${ }^{16}$. Há ameaça explícita de deposição. Na pauta das reivindicações dos jesuítas estava, dentre outras coisas, a acusação de que o "santo padre" era conivente com as heresias dos inimigos da religião: os "inovadores", os "anti-aristotélicos". E, como se disse, a reivindicação era a da ação com braço forte contra as heresias em troca de sua permanência frente à Igreja - ameaçada pela intervenção espanhola. É nesse mesmo ano (1632) que surge o Diálogo Sobre os Dois Máximos Sistemas do Mundo, de Galileu.

A obra, como o Saggiatore, cumpre com todas as exigências protocolares para a publicação, isso pressupõe um longo caminho até o prelo. Sobre seu conteúdo, é sabido que se trata de uma obra de astronomia, anti-aristotélica, que ao invés de apresentar uma hierarquia entre mundo celeste e mundo terrestre (Da geração e corrupção), defende uma homogeneidade entre esses dois mundos, "ambos formados de uma natureza comum, natureza toda e em todas as partes cognoscível como uma idêntica observação racional dos fenômenos ou "acidentes""17. Criticava também a teoria aristotélica da vida sobre a terra que, por geração e corrupção, era produzida por elementos contrários: depois da destruição a matéria é transformada em outro corpo totalmente diverso dela: do frio advém o calor, do úmido o seco, etc. Ao invés dessa teoria, preferiu uma posição atomista 
(indireta, é claro) que era a de se pensar não na destruição e corrupção, mas em movimentos locais de partes da matéria - "Galileu negava a escolástica e se atinha ao atomismo de Demócrito" 18 . Mas, o objetivo principal da referida obra era a defesa, também implícita, do sistema heliocêntrico de Copérnico; e a melhor forma de se fazer isso era atacando a astronomia de Aristóteles, com a defesa do atomismo de Demócrito. Só que tal teoria recai, de novo, no velho problema dos acidentes eucarísticos: assim como a matéria se corrompe em movimentos locais, os acidentes eucarísticos se corrompem, se alteram e mudam de natureza. Isso estava tudo muito implícito no Diálogo, visto que, em nenhuma vez sequer Galileu entra em questões de ordem religiosa. Mesmo assim, isso foi a gota d'água que faltava para uma nova acusação contra Galileu e, dessa vez, dado as pressões políticas contra Urbano VIII, não mais podia contar com a proteção do seu amigo.

O livro caiu nas garras dos jesuítas e, na pessoa do cientista ligado ao Colégio Romano, o padre Cristopher Scheiner, Galileu teve o seu primeiro opositor que procurou nas páginas que tratavam do problema da incorruptibilidade dos céus, a teoria materialista da "transmutação substancial". Sem maiores detalhes, antes que as acusações chegassem ao Santo Ofício (o que seria muito pior), o papa formou uma comissão particular, cuja presidência era de sua responsabilidade, para analisar a nova obra de Galileu, cujos resultados, depois de algumas sessões de reunião, fora o seguinte: Galileu foi acusado de desobediência às determinações de 1616 do cardeal Bellarmino, o que recaia em alta traição. Por isso, devia abjurar-se publicamente e, ainda, recolher-se em prisão domiciliar perpétua (condenação anunciada em 22 de junho de 1633) - o que ficou barato em vista da possibilidade de enfrentar diretamente o Santo Ofício, naquela época composto em sua maioria por jesuítas. Mas, resta salientar que a condenação foi por heresia inquisitorial, ou seja, disciplinar, não teológica ou doutrinal, o que em outras palavras significa dizer traição.

Com a decisão, o papa afasta todos os envolvidos no caso Galileu de Roma - os prós e os contra: dos amigos do florentino aos caluniadores jesuítas, incluindo o padre Grassi, e coloca o Diálogo no Índex. Mas, o que tem a ver o padre Grassi, aparentemente, tão distante da atual controvérsia com o Diálogo? Aqui o termo "aparentemente" cai muito bem. O padre Grassi denunciante protagonista no caso Galileu, sempre esteve nos bastidores, travestido de outras identidades, escamoteando como um camaleão. Seu rancor teria triunfado frente ao atomismo inovador que colocara o mistério da Eucaristia sob suspeita e, consequentemente, dado aos protestantes motivos para desmerecer as determinações de Trento. Sua morte em 1654 teria impedido, no entanto, que ele tivesse sido definitivamente coroado quando, em 1685, Luís XIV revoga o Edito de Nantes e anuncia a "conversão geral" dos protestantes franceses. Esse feito 
dá à Igreja um novo vigor, cancelando a crise gerada pela Reforma. O resultado foi o silêncio dos inovadores com a "interdição" das teorias atomistas - tudo iniciado por Grassi. Na esteira de Galileu viram-se também silenciados Pascal, Port-Royal, Malebranche, Gassendi, Descartes. Mas o atomismo não estava morto.

\section{Considerações finais}

Pretendíamos aqui apresentar uma nova versão da condenação de Galileu. Como foi alertado desde o início desse artigo, trata-se de uma versão de Pietro Redondi que em seu livro Galileu Herético (1991) afirma ter tido acesso aos autos da condenação de Galileu, com a autorização do Vaticano, e descobriu que a verdade oficial não condizia com o que realmente está registrado nos arquivos.

Certo é que sua obra promove um impacto na comunidade científica, bem como, um incômodo nas autoridades eclesiásticas. Tanto é que em 1998, ao lançar a Encíclica Fides et Ratio, João Paulo II pede perdão pelo erro da Igreja e diz: "Galileu, fiel e sincero, mostrou-se mais perspicaz do que seus adversários teólogos". A importância da revisão da história está no fato de que é aprendendo com os erros que avançaremos rumo aos acertos, pois "um povo que não conhece sua história está condenado a repeti-la", dizia o historiador Eduardo Bueno. O caso Galileu é um exemplo típico de que, para o avanço do conhecimento e da ciência, faz-se necessário fazer com que o homem esteja de pleno gozo da liberdade de pensamento e expressão.

${ }^{1} \mathrm{O}$ termo "Nous" é utilizado correntemente no mundo grego significando "mente", "intelecto", "razão".

${ }^{2}$ SPINELLI, Miguel. Filosofia e Ciência. São Paulo: EDICON, 1990. p. 76.

${ }^{3}$ SPINELLI, 1990, p. 104.

${ }^{4}$ REDONDI, Pietro. Galileu Herético. Trad. Julia Mainardi. São Paulo: Companhia das Letras, 1991. p. 107.

${ }^{5}$ REDONDI, Op. Cit., p. 21.

${ }^{6}$ REDONDI, Op. Cit., idem. Ibidem.

${ }^{7}$ REDONDI, Op. Cit., p. 16.

${ }^{8}$ REDONDI, Op. Cit., p. 66.

O atomismo herético de Galileu Galilei - Eduardo Simões 
${ }^{9}$ Vide REDONDI, 1991, p.38-40.

${ }^{10}$ REDONDI, Op. Cit., p. 39.

${ }^{11}$ REDONDI, Op. Cit., p. 51.

${ }^{12}$ REDONDI, Op. Cit., p. 67.

${ }^{13}$ REDONDI, Op. Cit., p. 238.

${ }^{14}$ REDONDI, Op. Cit., p.183.

${ }^{15}$ REDONDI, Op. Cit., p.185.

${ }^{16}$ REDONDI, Op. Cit., p. 256.

${ }^{17}$ REDONDI, Op. Cit., p. 262.

${ }^{18}$ REDONDI, Op. Cit., p. 264. 